\title{
Validating the questionnaire of factors influencing creative process for RN-BSN students in Taiwan
}

\author{
Ya-Lie Ku ${ }^{* 1}$, Pei-Yu Lee ${ }^{1}$, Chin-Tang Tu², Man-Hua Shen ${ }^{1}$, Chien-Lin Kuo ${ }^{1}$ \\ ${ }^{1}$ Department of Nursing, Fooyin University, Kaohsiung City, Taiwan, Republic of China \\ ${ }^{2}$ Center for Teacher Education, National Kaohsiung Normal University, Kaohsiung City, Taiwan, Republic of China
}

Received: September 21, 2014

Accepted: February 6, 2015

Online Published: March 9, 2015

DOI: $10.5430 /$ jnep.v5n5p55

URL: http://dx.doi.org/10.5430/jnep.v5n5p55

\begin{abstract}
The purpose of this study was to validate the questionnaire of factors influencing creative process as a valid and reliable instrument. The previous study was to generate 100 items for a creative process based on the content analysis of qualitative data from interviewing 18 Taiwanese nurses who received awards during 2009 - 2010 for developing creative nursing products. The content validity of the questionnaire for creative process was assured by having it evaluated by 5 experts and through discussion with our research team. A pilot study was tested with 30 RN-BSN students, and the questionnaire was revised to comprise 50 items that focused on the factors influencing creative process. A formal survey of nursing schools was conducted using the 50 items of the factors influencing creative process by selecting RN-BSN students from various nursing programs in Taiwan. This study was conducted from August 2012 to July 2013. Following Exploratory Factor Analysis (EFA), a total of 33 items of the factors influencing creative process were questions assessing the characteristics ( 9 items), abilities (10 items), barriers (7 items), and motivation ( 7 items). Cronbach's alpha values ranged from .86 to .92 for each scale, and the total explanation of variance ranged from $52.95 \%$ to $65.4 \%$. Following the Confirmatory Factor Analysis (CFA), 27 items-4 subscales on the factors influencing creative process were indicated as a validated model with all $\chi^{2} / P>0.05, \mathrm{GFI}>0.9, \mathrm{RMR}<0.5$, RMSEA $<$ 0.5 , AGFI $>0.9$. The questionnaire aimed at evaluating the influencing factors of creative process, due to its good validity and reliability, was considered as a concise and useful tool. The factors influencing creative process should be able to measure four variables comprising of characters, abilities, barriers, and motivation changed over time at difference levels following the teaching course in their further education of creative thinking.
\end{abstract}

Key Words: Tools, Instrument, Creativity, Nursing students

\section{INTRODUCTION}

General education and nursing education in Taiwan have emphasized on the creative-teaching and creative-thinking for almost ten years. ${ }^{[1-3]}$ Chao, Tai, and Chiu ${ }^{[4]}$ defined creativity as inspiring fluency, flexibility, and uniqueness and applying the knowledge to associate, transform, or reconstitute to fit the current needs or functional behaviours. The center of the creative concept on RN-BSN students is creative thinking energy, impacted by efforts to balance, influenced by the interaction of structuring work, self-esteem, and time to reflect. ${ }^{[5]}$ Therefore, the student nurses need to have creative related courses to arouse their producing ideas, designing activities applying divergent and convergent thinking and knowledge integration. Although some creative articles identified in the nursing were focused on teaching strategies in the classroom, ${ }^{[6-12]}$ there is a lack of nursing re-

\footnotetext{
*Correspondence: Ya-Lie Ku; Email: ns126@fy.edu.tw; Address: No. 151, Chin-Hsueh Rd., Ta-Liao District, Kaohsiung City 83102, Taiwan,
} Republic of China.

Published by Sciedu Press 
search in the evaluation of creative process to connect the gap between creative teaching and creative thinking. Therefore, $\mathrm{Ku} \& \mathrm{Kuo}^{[13]}$ developed a teaching framework of creative thinking in nursing education on the basis of the creative process for clinical nurses.

Following the teaching framework, the principal investigator developed the questionnaire of creative process. The previous study was to generate 100 items for a questionnaire of creative process based on the content analysis of qualitative data from interviewing 18 Taiwanese nurses who received awards during 2009 - 2010 for developing creative nursing products. The content validity of the CPQ was assured by having it evaluated by 5 experts and through discussion with our research team. A pilot study was tested with 30 RN-BSN students, and the questionnaire was revised to comprise 50 items that focused on the factors influencing CPQ due to the other 50 questions as difficult to answer because the majority of students did not have experience in conducting creative process in their nursing career.

\subsection{Purpose}

The purpose of this study was to validate the questionnaire of factors influencing creative process as a valid and reliable instrument.

\subsection{Literature review}

The literature review focused on education areas, since no articles were related to such areas in nursing, was on the basis of the results ${ }^{[13]}$ divided into four sections as characteristics, abilities, barriers, motivation for creativity. For the characteristics of creativity, Chen ${ }^{[14]}$ proposed that the characteristics of creative personality were curiosity, adventure, challenge, and imagination. Runco ${ }^{[15]}$ provided autonomy, self-control, strain, sensitivity, and tolerance of being ambiguous, and paradox as temperaments of creativity. $\mathrm{Yeh}^{[16]}$ indicated working hard, courage, self-confidence, perseverance, and optimism as the characteristics of creators. Regarding the abilities of creativity, Chen ${ }^{[14]}$ proposed sensitivity, fluency, flexibility, originality, and the elaboration of five creative abilities. $\mathrm{Ku}, \mathrm{Kuo}$, and Sheu ${ }^{[17]}$ defined creative nursing abilities in terms of fluency, flexibility, and uniqueness, suggesting that the total number of interventions nursing students could design for patient care, such as the ability of fluency, and the categories of interventions as the ability of flexibility, and the interventions that have never used in the clinical settings or found in the literature, but did work on the patients' care, as the ability of uniqueness.

Regarding barriers to creativity, Chen ${ }^{[14]}$ proposed three levels of individual aspect, problems-solving, environment and organization; the individual level included negative attitudes, lack of confidence, fear of being criticized, false sense of being successful, comparative tendency, negative experiences, lack of self-awareness, having positive feelings and emotions, familiar requests, compulsive obedience, habit and dependence, delusion and reminiscence, apathy and isolation. Problem-solving included thinking at only one-point, prejudgment, flippant answers, excessive thinking, lack of prudence, goals or plans, and of understanding about problems. The environment and organization levels included the influential factors of families, schools, and societies. Regarding the motivation for creativity, Lin and Chiou ${ }^{[18]}$ suggested that the intrinsic motivation was the most critical factor for creativity. Hsia ${ }^{[19]}$ conducted a study on influential factors of students' creativity in three levels of analysis, including students' motivation, teachers' creative teaching, and an innovative atmosphere among 3330 students and 333 teachers in 43 schools of Taiwan. The results indicated that the internal motivation of students, teachers' creative strategies, and the principal's encouragement of the students' creativity directly impacted the students' creativity.

\section{Method}

\subsection{Design and setting}

This study, which had a methodological and developmental design and employed a stepwise procedure, was conducted from August 2012 to July 2013 at an university in the southern Taiwan. Permission was obtained from the Ethics Committee from school (FYH-IRB-101-07-01-A).

\subsection{Participants}

Originally the study samples were used randomly selected RN-BSN students from 10 universities in Taiwan with approximate 500 students who have had working experiences. Finally, a total of 391 RN-BSN students were willing to participate in this study, approaching at $78.2 \%$ returned rate.

\subsection{Questionnaire}

The 50 items-questionnaire of factors influencing creative process included the basic information (10 items), characteristics (10 items), abilities (10 items), barriers (10 items), and motivation (10 items). The basic information included gender, age, married status, working years, position, professional levels, hospital style, experience of participating creative training or conference, experience of innovation, and self-evaluated own creative abilities by 1-10 point Visual Analogue Scale (VAS). The characteristics included speaking own opinions, insisting on completing nursing work, hearing other opinions, actively and optimistically completing nursing work, owning leadership, integrating nursing information, high curiosity for nursing works, thinking complex nursing work, perfectionist for nursing work, and like to 
purchase the new nursing products. The abilities included imagination, association, transformation, change, observation, imitation and innovation, action, alerting professional skills, searching new ideas, and actively providing altering methods. The barriers included unlikely change, lack of experts' assist, too busy and no time, lack of resources, environment, lack of education, team, and experiences on other areas, lack of innovative experiences, and routine nursing education. The motivation included interesting, achievement, capability, cross curdle, encouragement, promoting quality of life for patients, problem-solving, competence, passionate, and future nursing career trend.

\subsection{Data collection}

A formal survey of nursing schools was conducted using the 50 items of questionnaire about the factors influencing creative process by selecting RN-BSN students from various nursing programs in Taiwan. Two nursing programs in the north, two in the south, one in the east, and one in the central region of Taiwan were selected, and agreed to assist in the data collection among RN-BSN students. Data were collected from September, 2012 to May, 2013. Data collectors explained the purpose of this study to RN-BSN students and distributed the guides designed by the investigator that described the process of completing the questionnaire about factors influencing creative process and the benefits of participating in the study, as well as informed the participants the their responses were confidential, and that they had the freedom to withdraw at any time. The questionnaire of factors influencing creative process required approximately 20 minutes for RN-BSN students to complete. The students who completed the questionnaire were offered tickets worth NT\$100.

\subsection{Data analysis}

The statistical analysis in the study related to the validity and reliability of the instrument was performed using AMOS 21.0 and SPSS 14.0 (SPSS Inc., Chicago, IL, USA).

\section{Results}

\subsection{Demographics}

A total of $391 \mathrm{RN}-\mathrm{BSN}$ students participated in the study; $46.8 \%$ lived in the south and $35.8 \%$ lived in the north. They had a mean age of 27.14 years that ranged from 20 to 53 years; $96.9 \%$ were female, $78.5 \%$ were married, and $80.8 \%$ were employed (average 5.87 years; range: 0 - 30 years). In addition, $72.4 \%$ of the students were clinical nurses, $27.2 \%$ in the N0, $25.4 \%$ in the N3, and $28.5 \%$ were not in the advanced level. Moreover, $34.5 \%$ worked in the district hospital, and more than $90 \%$ had no creative training or creative

Published by Sciedu Press experience. According to a 1-10 point VAS, $69.1 \%$ of the 391 RN-BSN students perceived their creative abilities to be between levels 4 and 6, 20.6\% perceived their creative abilities to be between levels 7 and $9,10.3 \%$ perceived their creative abilities to be between levels 1 and 3 . The mean score was 5.27. The demographics of the $391 \mathrm{RN}-\mathrm{BSN}$ students were shown in Table 1.

However, only the responses of $316 \mathrm{RN}-\mathrm{BSN}$ students were selected into data analysis because they have had working experience in the clinical setting. A total of $316 \mathrm{RN}-\mathrm{BSN}$ students were divided into two groups of data analysis. The responses of 116 students were used for EFA and the responses of 200 students were used for CFA.

\subsection{Validity and reliability}

\subsubsection{Exploratory Factor Analysis (EFA) of the question- naire $(N=116)$}

Through EFA, a total of 33 items in the questionnaire of factors influencing creative process were questions assessing the characteristics (9 items), abilities (10 items), barriers (7 items), and the motivation (7 items). Cronbach's alpha values ranged from .86 to .92 for each scale and the total explanation of variance ranged from $52.95 \%$ to $65.4 \%$. Regarding the scale of the characteristics (Cronbach's alpha .89), two subscales were labeled as Openness and Perseverance (Cronbach's alpha .77), Thinking and Integration (Cronbach's alpha .86) with $54.77 \%$ of explaining variance. The Cronbach's alpha for the scale of the abilities was .92 with $52.95 \%$ of explaining variance. Regarding the scale of the barriers (Cronbach's alpha .89), two subscales were labeled as Resources and Working Environment (Cronbach's alpha $.82)$, Training and Cooperation (Cronbach's alpha .88) with $65.4 \%$ of explaining variance. Regarding the scale of motivation (Cronbach's alpha .86), two subscales were labeled as Achievement and Self-Confidence (Cronbach's alpha .83), Professional Growth (Cronbach's alpha .81) with $62.77 \%$ of explaining variance. The EFA of the factors influencing creative process were shown in Table 2.

\subsubsection{Confirmatory Factor Analysis (CFA) of the Ques- tionnaire $(N=200)$}

Following CFA by using AMOS 21.0, the four scales were indicated as a validated model with all $\chi^{2} / P>0.05$, GFI $>$ $0.9, \mathrm{RMR}<0.05, \mathrm{RMSEA}<0.1$, AGFI $>0.9 .^{[20]}$ The 27 validated items of the questionnaire of factors influencing creative process were questions assessing the characteristics ( 8 items), abilities (6 items), barriers (6 items), and motivation (7 items). The two subscales of the characteristics scale were Openness and Perseverance ( 3 items) and Thinking and Integration (5 items). The two subscales of the abilities scale were Association ( 2 items) and Change (4 items). The two 
sub scales of the barriers scale were Resources and Working ment and Self- Confidence ( 3 items), Professional Growth (4 Environment (3 items), Training and Cooperation (3 items). items).

The two subscales of the motivation scale were Achieve-

Table 1. Demographics of the RN-BSN students in Taiwan $(\mathrm{N}=391)$

\begin{tabular}{|c|c|c|c|c|c|}
\hline Variables & $\mathbf{n}$ & $\%$ & $\mathrm{M} \pm \mathrm{SD}$ & Maximum & Minimum \\
\hline \multicolumn{6}{|l|}{ Location } \\
\hline North & 140 & 35.8 & & & \\
\hline Central & 36 & 9.2 & & & \\
\hline South & 183 & 46.8 & & & \\
\hline Eastern & 32 & 8.2 & & & \\
\hline \multicolumn{6}{|l|}{ Gender } \\
\hline Male & 12 & 3.1 & & & \\
\hline Female & 377 & 96.9 & & & \\
\hline Age & & & $27.14 \pm 6.37$ & 53 & 20 \\
\hline \multicolumn{6}{|l|}{ Marriage Status } \\
\hline Married & 78 & 19.9 & & & \\
\hline Single & 307 & 78.5 & & & \\
\hline Divorce & 6 & 1.5 & & & \\
\hline \multicolumn{6}{|l|}{ Job } \\
\hline Have & 316 & 80.8 & & & \\
\hline None & 75 & 19.2 & & & \\
\hline Work years & & & $5.87 \pm 6.01$ & 30 & 0 \\
\hline \multicolumn{6}{|l|}{ Job titles } \\
\hline Clinical nurses & 280 & 72.4 & & & \\
\hline Clinical Nursing Specialist & 13 & 3.4 & & & \\
\hline Leader & 1 & 0.3 & & & \\
\hline Head nurse & 3 & 0.8 & & & \\
\hline None & 90 & 23.3 & & & \\
\hline \multicolumn{6}{|l|}{ Advanced level } \\
\hline $\mathrm{N}_{0}$ & 105 & 27.2 & & & \\
\hline $\mathrm{N}_{1}$ & 43 & 11.1 & & & \\
\hline $\mathrm{N}_{2}$ & 98 & 25.4 & & & \\
\hline $\mathrm{N}_{3}$ & 25 & 6.5 & & & \\
\hline $\mathrm{N}_{4}$ & 5 & 1.3 & & & \\
\hline None & 110 & 28.5 & & & \\
\hline \multicolumn{6}{|l|}{ Hospital type } \\
\hline Local & 80 & 22.5 & & & \\
\hline District & 122 & 34.3 & & & \\
\hline Medical center & 56 & 15.7 & & & \\
\hline Others & 98 & 27.5 & & & \\
\hline \multicolumn{6}{|l|}{ Creative training } \\
\hline Have & 36 & 9.4 & & & \\
\hline None & 347 & 90.6 & & & \\
\hline \multicolumn{6}{|l|}{ Creative experiences } \\
\hline Have & 15 & 3.9 & & & \\
\hline None & 372 & 96.1 & & & \\
\hline \multicolumn{6}{|l|}{ Self-perception of creativity } \\
\hline $1-3$ & 31 & 10.3 & & 10 & 1 \\
\hline $4-6$ & 208 & 69.1 & $5.27 \pm 1.51$ & 10 & $\perp$ \\
\hline $7-9$ & 62 & 20.6 & & & \\
\hline
\end{tabular}


Table 2. Exploratory Factor Analysis (EFA) for the four subscales of CPQ $(N=116)$

\begin{tabular}{|c|c|c|c|c|}
\hline Subscales & $\mathbf{M}$ & SD & Factor loading & Cronbach's Alpha \\
\hline \multicolumn{5}{|l|}{ Characters } \\
\hline 2 & 4.10 & .638 & .561 & \\
\hline 3 & 4.29 & .528 & .752 & \\
\hline 4 & 4.18 & .654 & .813 & \\
\hline Openness and Perseverance & & & & .77 \\
\hline 5 & 3.33 & .863 & .700 & \\
\hline 6 & 3.58 & .846 & .705 & \\
\hline 7 & 3.69 & .796 & .657 & \\
\hline 8 & 3.28 & 1.011 & .795 & \\
\hline 9 & 3.40 & .864 & .668 & \\
\hline 10 & 3.19 & .884 & .522 & \\
\hline Thinking and Integration & & & & .86 \\
\hline Total explain $54.77 \%$ (9 items) & & & & .89 \\
\hline \multicolumn{5}{|l|}{ Abilities } \\
\hline 1 & 3.67 & .720 & .731 & \\
\hline 2 & 3.70 & .701 & .793 & \\
\hline 3 & 3.56 & .726 & .724 & \\
\hline 4 & 3.54 & .806 & 646 & \\
\hline 5 & 3.91 & .680 & .715 & \\
\hline 6 & 3.67 & .720 & 685 & \\
\hline 7 & 3.84 & .632 & .700 & \\
\hline 8 & 3.60 & .756 & .760 & \\
\hline 9 & 3.59 & .758 & .748 & \\
\hline 10 & 3.70 & .737 & .763 & \\
\hline Total explain 52.95\% (10 items) & & & & .92 \\
\hline \multicolumn{5}{|l|}{ Barriers } \\
\hline 3 & 3.99 & .808 & .622 & \\
\hline 4 & 3.89 & .743 & .807 & \\
\hline 5 & 3.90 & .773 & .753 & \\
\hline Resources and Working Environment & & & & .82 \\
\hline 6 & 3.84 & .798 & .615 & \\
\hline 7 & 3.73 & .817 & .734 & \\
\hline 8 & 3.73 & .795 & .894 & \\
\hline 9 & 3.83 & .701 & .724 & \\
\hline Training and Cooperation & & & & .88 \\
\hline Total explain $65.4 \%$ (7 items) & & & & .89 \\
\hline \multicolumn{5}{|l|}{ Motivation } \\
\hline 1 & 3.53 & .751 & .502 & \\
\hline 2 & 3.90 & .727 & .904 & \\
\hline 3 & 3.82 & .753 & .829 & \\
\hline Achievement and Self-Confidence & & & & .83 \\
\hline 5 & 3.43 & .877 & .493 & \\
\hline 8 & 3.83 & .663 & .792 & \\
\hline 9 & 3.78 & .708 & .856 & \\
\hline 10 & 3.95 & .696 & 642 & \\
\hline Professional Growth & & & & .81 \\
\hline Total explain $62.77 \%$ (7 items) & & & & .86 \\
\hline
\end{tabular}

Each construct was regressed on the path with observed respectively. The second character were "Thinking and Intevariables with a single arrow and factor loadings. Each ob- gration", with factor loadings of five characters as .66, .75, servable variable was combined with the measurement errors. $.71, .71, .46$, and errors of $.43, .57, .50, .51, .21$, respectively. For the latent construct of the characteristics, the first charac- The first character moderately correlated with the second ter were "Openness and Perseverance" with factor loadings character (.48). The CFA for the scale of characteristics of three characters as $.74, .68, .82$, and errors of $.55, .46, .68$, among 200 RN-BSN students was shown in Figure 1. 
For the latent construct of the abilities, the first ability were "Association" with factor loadings of two abilities as .66, .67, and errors of $.46, .45$, respectively. The second ability were "Change" with factor loadings of four abilities as .63, .71,.75, .59 , and errors of $.40, .50, .57, .35$, respectively. The first ability highly correlated with the second character (.80). The CFA for the scale of abilities among 200 RN-BSN students was shown in Figure 2.

For the latent construct of the barriers, the first observed variable were "Resources and Working Environment" with factor loadings of three barriers as .53, .82, .79, and errors of $.28, .68, .62$, respectively. The second observed variable were "Training and Cooperation" with factor loadings of three barriers as $.83, .87, .83$, and errors of .68, .76, .68, respectively. The first barrier highly correlated with the second barrier (.82). The CFA for the scale of barriers among 200
RN-BSN students was shown in Figure 3.

For the latent construct of the motivation, the first observed variable were "Achievement and Self- Confidence" with factor loadings of three motivation as $.76, .86, .83$, and errors of $.57, .75, .68$, respectively. The second observed variable were "Professional Growth" with factor loadings of four motivation as $.29, .86, .95, .78$, and errors of .08, .74, .90, .61, respectively. The first motivation highly correlated with the second motivation (.82). The CFA for the scale of motivation among 200 RN-BSN students was shown in Figure 4.

Following the CFA, 27 items-4 subscales of the factors influencing CPQ were indicated as a validated model with all $\chi^{2} / P>.05$, GFI $>.9$, RMR $<.5$, RMSEA $<.5$, AGFI $>.9$. The CFA of the questionnaire of factors influencing creative process and 27 items were shown in Table 3 and Table 4.

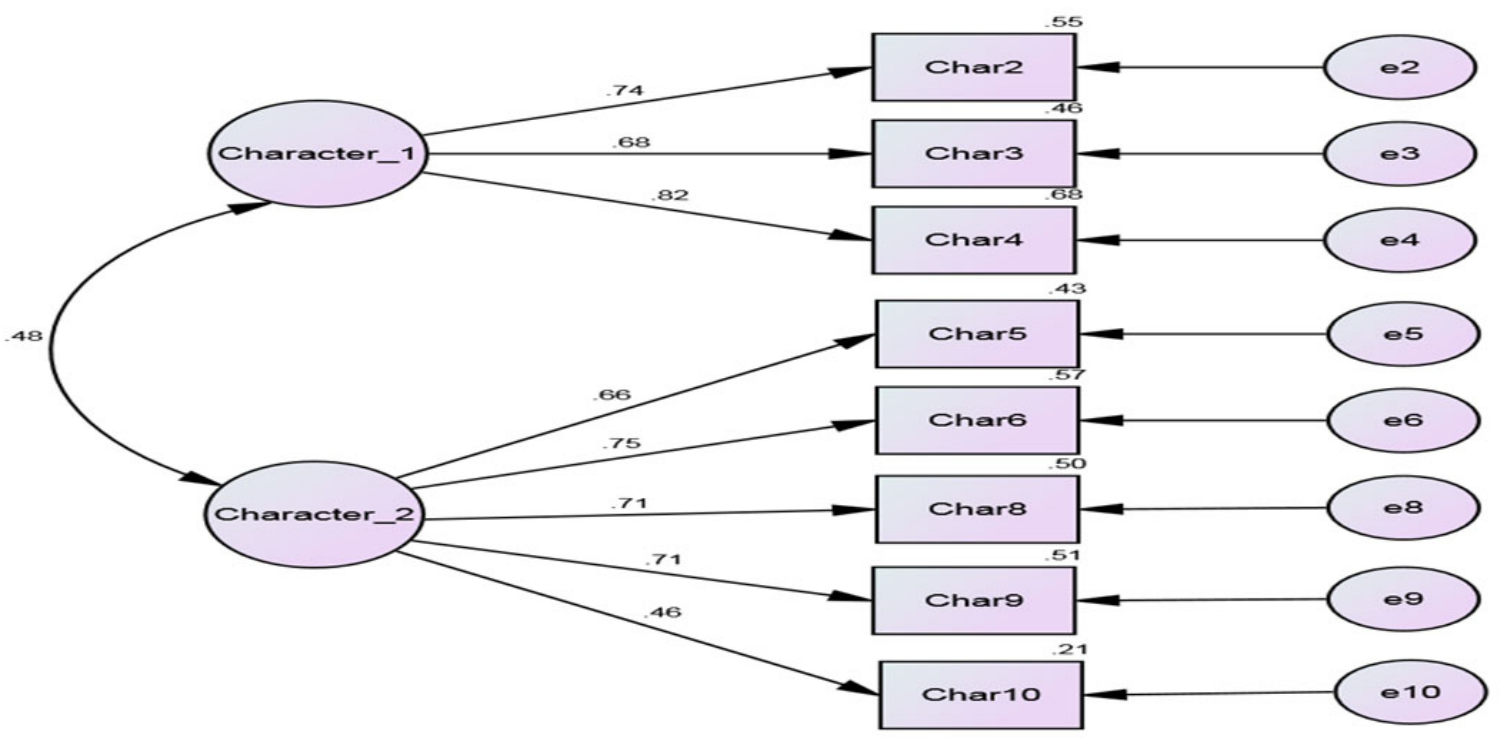

Figure 1. CFA for the scale of characteristics among 200 RN-BSN students

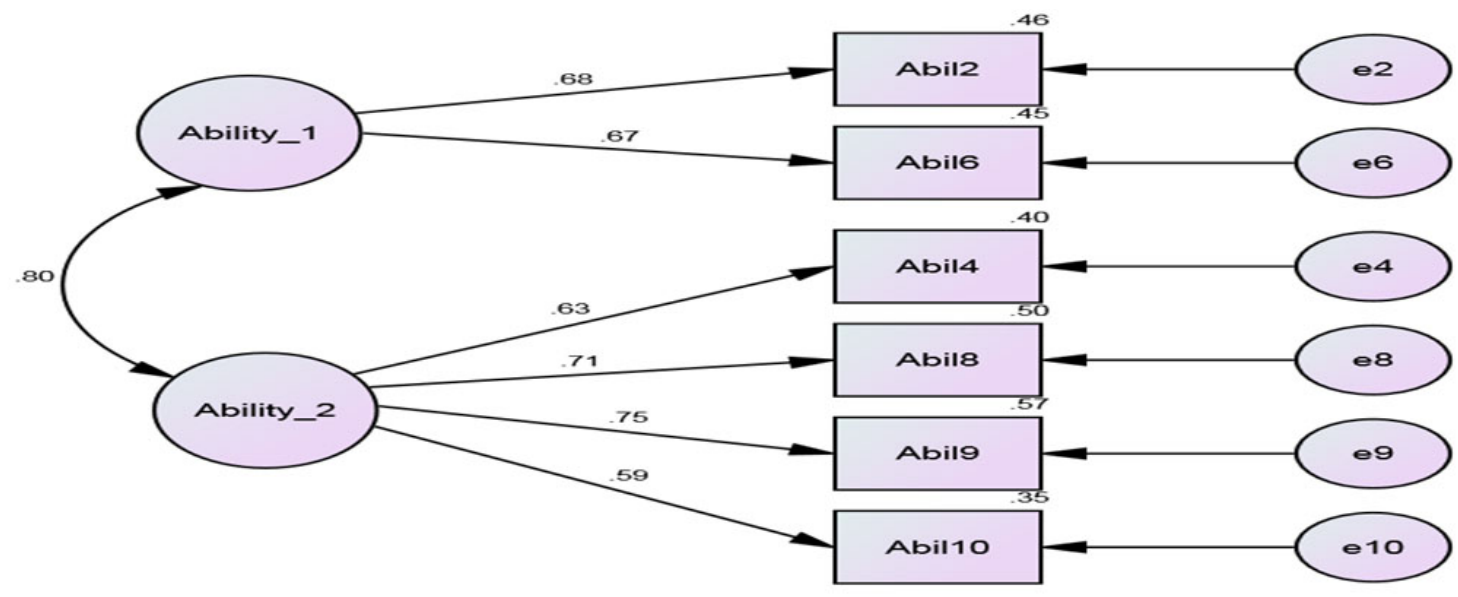

Figure 2. CFA for the scale of abilities among 200 RN-BSN students 


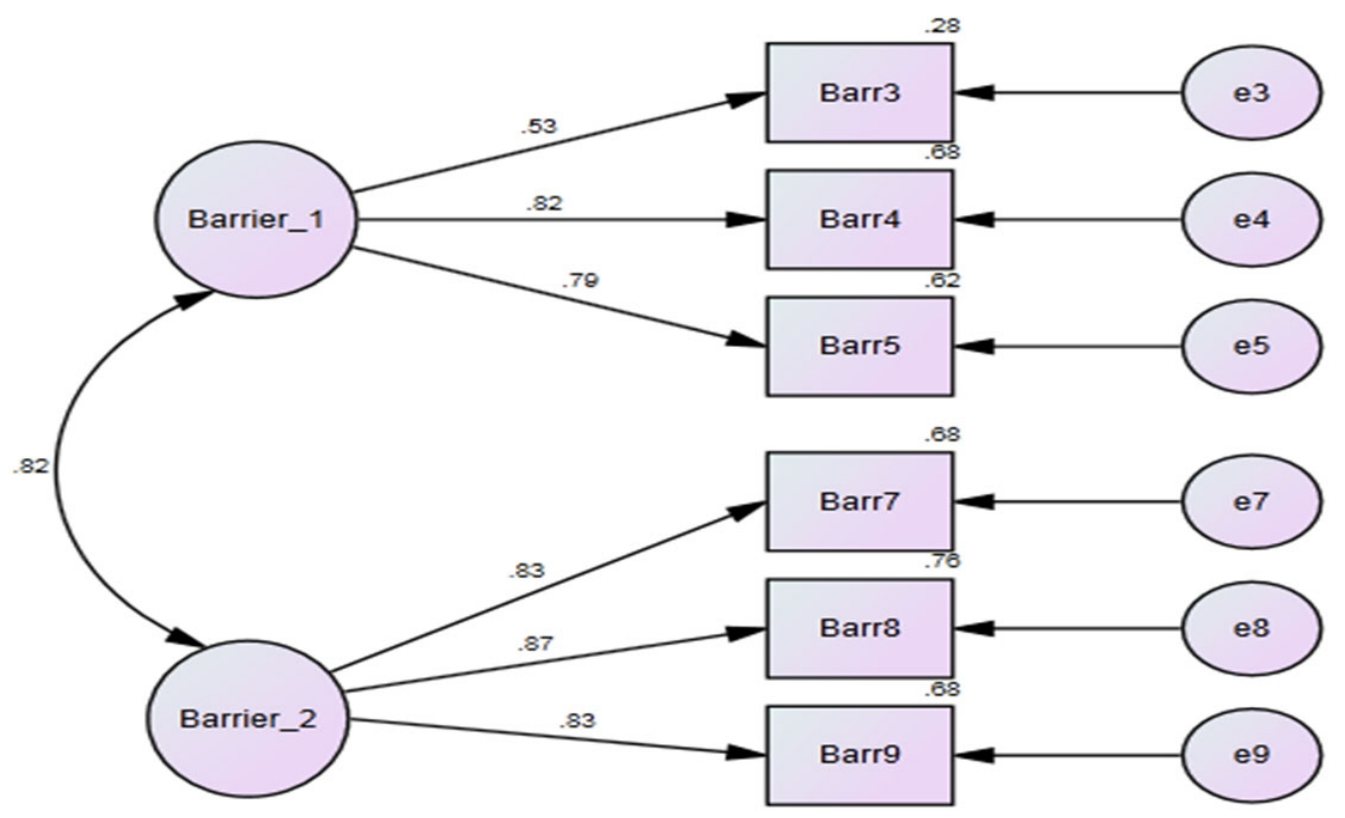

Figure 3. CFA for the scale of barriers among 200 RN-BSN students

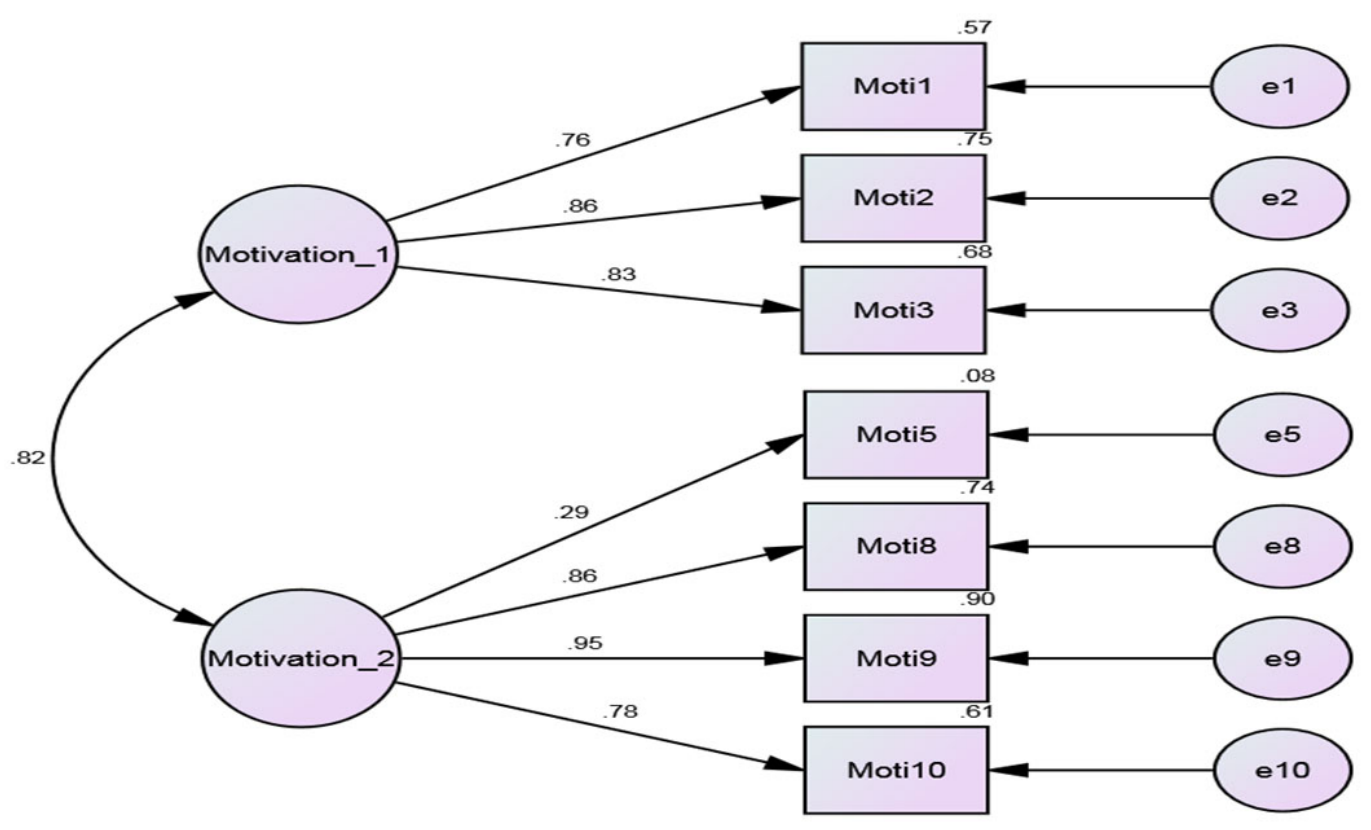

Figure 4. CFA for the scale of motivation among 200 RN-BSN students

Table 3. The overall model fit $(\mathrm{N}=200)$

\begin{tabular}{llllllll}
\hline Subscales & $\chi^{\mathbf{2}}$ & $\chi^{\mathbf{2}} / \mathbf{d} \boldsymbol{f}$ & $\boldsymbol{P}$ & $\mathbf{C F I}$ & RMSEA & TLI & GFI \\
\hline Characters & 28.236 & 19 & .079 & .981 & .049 & .972 & .965 \\
Abilities & 12.534 & 8 & .129 & .986 & .053 & .973 & .980 \\
Barriers & 12.203 & 8 & .142 & .993 & .051 & .987 & .980 \\
Motivation & 20.754 & 13 & .078 & .991 & .055 & .985 & .972 \\
\hline
\end{tabular}


Table 4. 27 items of Creative Process Questionnaire (CPQ)

\begin{tabular}{|c|c|}
\hline Subscales & Items \\
\hline \multicolumn{2}{|l|}{ Characters } \\
\hline Openness and Perseverance & $\begin{array}{l}\text { 2. I will persist in completing every nursing practicum work. } \\
\text { 3. I can hear different points of view from others for nursing practicum work. } \\
\text { 4. I can actively and optimistically complete the nursing practicum work. }\end{array}$ \\
\hline Thinking and Integration & $\begin{array}{l}\text { 5. I feel myself owned the character of being a leader for nursing practicum work. } \\
\text { 6. I like to integrate different information for nursing practicum. } \\
\text { 8. I like to think complex nursing practicum work. } \\
\text { 9. I am a perfectionist for nursing practicum work. } \\
\text { 10. I bravely buy the new nursing practicum products in the market. }\end{array}$ \\
\hline \multicolumn{2}{|l|}{ Abilities } \\
\hline Association & $\begin{array}{l}\text { 2. I have the ability of association for nursing practicum work. } \\
6 \text {. I have the ability of imitation and innovation for nursing practicum work. }\end{array}$ \\
\hline Change & $\begin{array}{l}\text { 4. I have the ability to change for nursing practicum work. } \\
8 \text {. I have the ability of change professional skills for nursing practicum work. } \\
\text { 9. I have the ability of searching new ideas and information for nursing practicum work. } \\
\text { 10. I have the ability to actively propose the improved protocol when facing the problems } \\
\text { of nursing work. }\end{array}$ \\
\hline \multicolumn{2}{|r|}{ ( } \\
\hline Resources and Working & 3. I do not have extra time to conduct nursing practicum creation due to too busy job. \\
\hline Environment & $\begin{array}{l}\text { 4. Lack of equipments and resources might hinder me conduct nursing practicum creation. } \\
\text { 5. Too institutionalism of working environment would impede me conduct nursing practicum } \\
\text { creation. }\end{array}$ \\
\hline Training and Cooperation & $\begin{array}{l}\text { 7. Lack of organization cooperation might hider me conduct nursing practicum creation. } \\
\text { 8. Lack of cross-areas experiences would impede me conduct nursing practicum creation. } \\
\text { 9. Lack of experiences about practicum creation might disturb me conduct nursing practicum } \\
\text { creation. }\end{array}$ \\
\hline Motivation & 1. I am very interested in nursing practicum creation. \\
\hline $\begin{array}{l}\text { Achievement and Self- } \\
\text { Confidence }\end{array}$ & 2. Creating the new nursing products would make me feel achievement. \\
\hline Professional Growth & $\begin{array}{l}\text { 5. My serving unit encouraged members conduct nursing practicum creation a lot. } \\
\text { 8. Nursing practicum creation could promote my professional abilities. } \\
\text { 9. Nursing practicum creation could improve the passionate toward my profession. } \\
\text { 10. Nursing practicum creation is the trend for future nursing developing. }\end{array}$ \\
\hline
\end{tabular}

\section{Discussion AND CONCLUSION}

The final 27 items of the validated factors influencing creative process were questions assessing the characteristics (8 items), abilities (6 items), barriers (6 items) to, and motivation (7 items). The characteristics of the factors influencing CPQ included openness and perseverance, thinking and integration, which were similar to Yeh's ${ }^{[16]}$ proposition of creative personality. The abilities of the factors influencing creative process were association and change, which were similar to the concepts of fluency, flexibility, and uniqueness proposed by Chen ${ }^{[14]}$ and $\mathrm{Ku}, \mathrm{Kao}$, and Sheu. ${ }^{[17]}$ The barriers of the factors influencing creative process were resources, working environment, training, and cooperation, which were focused on the level of environment and organization regarding to the creative atmosphere of schools and societies. ${ }^{[14]} \mathrm{Hsia}^{[19]}$ also conducted a study on influential creative factors among 3330 students and found that teachers' creative teaching, and school innovative atmosphere directly impacted on the students' creativity. The motivation of the factors influencing creative process included achievement, self-confidence, and professional growth, which belong to intrinsic motivation, were similar to those reported in Lin and Chiou ${ }^{[18]}$ and 
Hsia's ${ }^{[19]}$ proposition of internal motivation as the critical and direct factor influencing students' creativity. Additionally, Kalischuk and Thorpe ${ }^{[5]}$ reported that the creative concepts among 12 RN-BSN students were creative thinking energy, which was influenced by the characteristics of self-esteem, barriers to balancing working, and availability of time and resources, that were similar to the factors of motivation and barriers influencing creative process. Finally, Chan ${ }^{[21]}$ systematically reviewed 8 articles about creative thinking in nursing education and identified four major themes as diversity learning, freedom to learn, learning with confidence, and learning through group work, which were also similar to the factors of motivation and barriers influencing creative process.

Overall, the majority of 391 nursing students competed the questionnaire were female, married, employed as the clinical nurses, and lived in the north and south areas of Taiwan; however, most of them did not have creative training or creative experiences and self-perceived creative abilities in the moderate level as 5.27 by a $1-10$ point VAS. The factors influencing creative process was a self-reported questionnaire aimed at evaluating the factors influencing creative process during nursing education. The results of this investigation showed that the psychometric characteristics of the Chinese version of the factors influencing creative process are promising the good reliability and validity as the essential qualities of a good instrument. The Cronbach's alpha coefficients of the factors influencing creative process achieved acceptable standards for reliability from .86 to .92 with the total explanation of variance ranged from $52.95 \%$ to $65.4 \%$. The construct validity of the Chinese version of the factors influencing creative process was evaluated by the CFA as indicating the validated model for four subscales with 27 items. This creative process, which has 27 items comprising of four variables as character, ability, barrier and motivation, aimed at evaluating the influencing factors of creative pro- cess, due to its good validity and reliability, was considered as a concise and useful tool. The factors influencing creative process should be able to measure four variables changed over time at difference levels following the teaching course in their further education of creative thinking. Therefore, the factors influencing creative process could be used to provide feedback to teachers who plan to evaluate the effectiveness of their creative related courses.

\section{Limitation}

There are some limitations in this study. First of all, because the samples of RN-BSN students were self-selected, the findings could not generalize to the population of RN-BSN students in Taiwan. Additionally, it is not clear if the validated factors influencing creative process could fit non-licensed groups or various cultures of nursing students. Finally, the validating process was on the part of the framework focused on the factors influencing the creative process in RN-BSN students. It is suggested that the remaining variables in the conceptual framework be validated in future studies of nursing faculties.

\section{ACKNOWLEDGEMENTS}

The author wishes to thank the National Science Council for supporting this study (Grant no. 101-2511-S-242-002) and also extends special thanks to all clinical RN-BSN students from the different hospitals for their participation and cooperation. Additionally, most sincere thanks are extended to the two part-time research assistants who conducted the data collection and organization. Finally, the author would express appreciation to the dean of the Nursing College and head of the Nursing Department, Fooyin University, for their administration support.

\section{CONFLICTS OF INTEREST DISCLOSURE}

The authors declare that there is no conflict of interest statement.

\section{REFERENCES}

[1] Minister of Education. Taiwan Creative Education, 2004. Available from: http://www.creativity.edu.tw

[2] Nursing Magazine. The National Union of Nurses' Assocation, 2003. Available from: http://www.nurse.org.tw

[3] Taiwan Nurse Association Message. Taiwan Nurse Association, 2005. Available from: http: //www.twna.org.tw

[4] Chao CY, Tai YK, Chiu SI. A study of the teaching effectiveness of automotive practical course with creative-thinking instructional strategy at the department of automobile of vocational high school. Journal of Technology Management. 2005; 10(1): 73-100.
[5] Kalischuk RG, Thorpe K. Thinking creativity: From nursing education to practice. The Journal of Continuing Education in Nursing. 2002; 33(4): 155-163. PMid:12180769

[6] Hsu LL, Chang MY, Hsieh SI. Mind mapping: A new tool for enhancing student learning strategy. Journal of Nursing. 2008; 55(2): 76-80. PMid:18393212

[7] Karadag M, Saritas S, Erginer E. Using the "six thinking hats"model of learning in a surgical nursing class: sharing experience and student opinions. Australian Journal of Advanced Nursing. 2009; 26(3): 59-69.

[8] Ku YL. Six thinking hats applied in the course of clinical case study and practicum III. Paper session presented at the 7th International 
Conference on Education, Research \& Training Institute of East Aegean, National \& Kapodistrian University of Athens, Greece, 2011.

[9] $\mathrm{Ku} \mathrm{YL.} \mathrm{Evaluating} \mathrm{creative} \mathrm{thinking} \mathrm{of} \mathrm{RN-BSN} \mathrm{students} \mathrm{in} \mathrm{the}$ course of clinical case study and practicum. Innovations in Education and Teaching International. 2013; 50(4): 1-10. http://dx.doi .o rg/10.1080/14703297.2013.838144

[10] $\mathrm{Ku} \mathrm{YL,} \mathrm{Chang} \mathrm{CF,} \mathrm{Kuo} \mathrm{CL,} \mathrm{et} \mathrm{al.} \mathrm{The} \mathrm{application} \mathrm{of} \mathrm{creative} \mathrm{think-}$ ing teaching in nursing education. Journal of Nursing. 2010; 57(2): 93-98. PMid:20401872

[11] Ku YL, Shen MH, Lee PY, et al. Constructing and evaluating a nursing capstone course for cultivating creativity in RN-BSN students in Taiwan. Journal of Nursing Education and Practice. 2014; 4(7): 1-10. http://dx.doi.org/10.5430/jnep.v4n7p175

[12] Ku YL, Shen MH, Lee PY, et al. The application of creative thinking teaching in the course of nursing capstone project. Chang Gung Nursing. 2014; 25(2): 157-166.

[13] Ku YL, Kuo CL. Develop a teaching framework of creative thinking in nursing education on the creative process of clinical nurses in Taiwan. Innovations in Education and Teaching International. 2014 51(1): 1-11. http://dx.doi.org/10.1080/14703297.2014.9 49282
[14] Chen LN. Creative Thinking Teaching Theory and Practice, 2008. Taipei: PSY.

[15] Runco MA. Creativity: Theories and Themes: Research, Development, and Practice. In J. H. Chiou et al. translators, 2008. Taipei: PSY.

[16] Yeh GF. Principles and Application of Innovation, 2011. Taipei: Yang-Chih Book.

[17] $\mathrm{Ku}$ YL, Kao Lo CH, Sheu S. The application of creative teaching strategies into the teaching protocol of nursing concepts. Journal of Nursing. 2003; 50(3): 83-87.

[18] Lin PF, Chiou H. Construction and related study of the inventory of self-efficacy for creative teaching. Journal of Educational Research and Development. 2008; 4(1): 141-170.

[19] Hsia CC. A study on influential factors of students' creativity: the three-level analysis as analytic framework. Journal of Special Education. 2011; 33: 151-178.

[20] Rong TS. AMOS and Research Method: Analysis of Moment Structures, 2009. Taipei: Wu-Nan Book.

[21] Chan ZCY. A systematic review of creative thinking/creativity in nursing education. Nurse Education Today. 2013; 33(11): 13821387. PMid:23044463 http://dx.doi.org/10.1016/j.nedt. 2012.09.005 